\title{
Control of Downy Mildew in Greenhouse-Grown Cucumbers Using Blue Photoselective Polyethylene Sheets
}

\author{
Reuven Reuveni, Division of Plant Pathology, and Michael Raviv, Division of Organic Agriculture and Horticul- \\ ture, ARO, Newe Ya'ar Research Center, P.O. Box 1021, Ramat Yishay 30095, Israel
}

\begin{abstract}
Reuveni, R., and Raviv, M. 1997. Control of downy mildew in greenhouse-grown cucumbers using blue photoselective polyethylene sheets. Plant Dis. 81:999-1004.

Six types of polyethylene sheets with or without a blue pigment, having an absorption peak at the yellow part of the spectrum $(580 \mathrm{~nm})$, in combination with three levels of UV-B (280 to 320 $\mathrm{nm}$ ) absorbance, were investigated for their effects on sporangial production and colonization of Pseudoperonospora cubensis on cucumbers in growth chambers. The effect of these photoselective sheets on the epidemiology of downy mildew in greenhouse-grown cucumbers has been investigated in several locations. The addition of the blue pigment to the films resulted in a significant inhibition of colonization and sporangial production of $P$. cubensis, whereas filtration of the UV spectrum enhanced the colonization but had no effect on the sporangial production. The appearance of the first symptom-bearing plants was delayed under the blue covers, and consequently, a significant reduction in the disease incidence of downy mildew was recorded under all blue sheets at each corresponding level of UV-B transmittance in five different field experiments through four seasons. Regardless of the differences in disease incidence, there were no significant differences among the yields that were obtained under the various sheets, probably due to the lower photosynthetically active radiation transmissivity of the blue films. The optimal features required for a desirable commercial sheet are discussed.
\end{abstract}

Plants are grown under cover in order to moderate nighttime heat losses due to radiation, convection, and conduction. The cover should allow maximum photosynthetically active radiation (PAR) into the greenhouse during the daylight hours to support optimal plant growth. Therefore, the climate in the greenhouse is essentially warm, humid, and wind-free (3) and provides an ideal environment for the development of many foliar diseases (4). The most common foliar diseases of greenhouse-grown cucumbers in Israel are gray mold, caused by Botrytis cinerea, and downy mildew, caused by Pseudoperonospora cubensis. The continuous use of a narrow range of pesticides in a monocrop system exerts intensive selection pressure for pesticide-resistant races of the pathogens, as has been reported for benomyl and metalaxyl (5). Moreover, the appearance of a resistant strain and its further establishment and survival for long periods increase the risk of reinforcing resistant pathogen populations by the renewed use of effective fungicides (22).

Corresponding author: R. Reuveni

E-mail: vfnrreuv@volcani.agri.gov.il

Contribution from the Agricultural Research Organization, The Volcani Center, Bet-Dagan, Israel. No. 1888-E, 1996 series.

Accepted for publication 14 April 1997.

Publication no. D-1997-0715-01R

(C) 1997 The American Phytopathological Society
As light is involved in the pathogenic processes of several foliar diseases, light transmitted through the greenhouse covers is currently the sole controllable factor in the spread of foliar diseases in unheated and passively ventilated low-technology walk-in tunnels and greenhouses, where relative humidity $(\mathrm{RH})$ is frequently very close to $100 \%$ at night, as reviewed recently (16). UV-B radiation (280 to 320 $\mathrm{nm}$ ) induces sporulation in $B$. cinerea and other pathogenic fungi, while monochromatic blue light inhibits this process $(2,6,8,9,15)$. Tan and Epton (23) clearly demonstrated that sporulation in some $B$. cinerea isolates, which occurs in the dark, can be inhibited by blue light. In fungi, light acts in many cases as a stress-inducing agent and results in morphogenetic changes, including spore production and germination. These findings suggest that careful modification of the light spectrum might efficiently reduce spore production and germination. According to Hite (7), the control of light quality can be used to reduce the inoculum potential of $B$. cinerea in the greenhouse. Partial control of gray mold on cucumber and tomato has been reported by Honda et al. (10), who used vinyl films that absorb UV light shorter than $390 \mathrm{~nm}$. Sasaki et al. (20) claimed that the part of the UV spectrum active in reduction of sporulation is 300 to $340 \mathrm{~nm}$. Control of early blight of greenhouse tomato caused by Alternaria solani has also been achieved by inhibition of sporulation by means of UV-absorbing vinyl film (24).
However, Jordan and Hunter (14) found higher, rather than lower, levels of Botrytis infection on strawberries grown under several colored polyethylene (PE) films compared with those grown under clear PE films or glass. In this case, the blue PE caused two synergistic phenomena related to Botrytis infection: etiolated plants and decreased vapor pressure deficit and temperature.

Illumination with blue light has been reported to inhibit sporangial production of $P$. cubensis in infected cucumber leaves (12), but no practical use of this finding was suggested. In a previous study, spectrally modified PE sheets with various ratios of blue to UV-B transmission were investigated for their effects on the epidemiology of gray mold caused by the fungus $B$. cinerea. The results showed a remarkable reduction in sporulation of $B$. cinerea (19) as well as a slower rate of gray mold epidemic development on tomatoes in greenhouses covered with PE sheet having a high blue/UV transmittance ratio (18). The pigment used in this sheet caused light absorption with a peak at $580 \mathrm{~nm}$. In the winter of 1990, a significant reduction of the spread of downy mildew on cucumbers was observed in commercial walk-in tunnels under blue polyethylene sheets compared with commercial IR-absorbing sheets. The disease appeared under the blue sheet only on the young leaves at the top of the plants compared with early attack on lower leaves under the IR-absorbing control sheet.

This finding led us to a continuing effort to develop a new PE sheet for the control of downy mildew on greenhouse-grown cucumbers. It should be emphasized that absorbing PAR necessarily affects plants' photosynthesis in a negative manner. The expected yield reduction must therefore be compensated by lower disease-related yield losses or by lower expenses on fungicides.

This paper summarizes investigations conducted over four seasons under both growth chamber and unheated and passively ventilated greenhouse conditions. The films were developed in collaboration with Ginegar Plastics, Israel.

\section{MATERIALS AND METHODS}

PE sheets. Six types of PE sheets with or without a blue pigment that absorbs part of the spectrum (absorption peak at 580 $\mathrm{nm}$ ), and that also exhibit various levels of UV-B (280 to $320 \mathrm{~nm}$ ) absorbance, were 
manufactured by Ginegar Plastics, Israel, and used in this research. All sheets contained an infrared absorber. Light transmittances of six types of PE sheets were recorded by a Cary 2300 spectrometer, and a representative reading is presented in Figure 1. Measurements with a spectrora- diometer (Li-Cor 1800) under sunlight conditions revealed similar light transmittance values.

The definitions for the sheets are as follows:

Sheet 1: without UV-B absorber ( $0 \%$ absorbance).

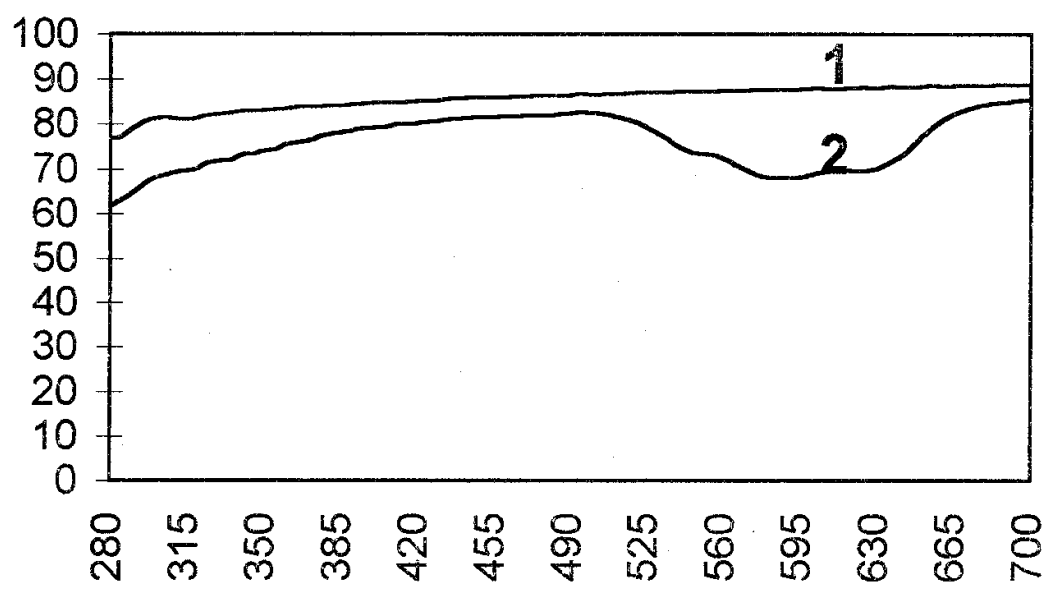

Sheet 2: same as $1+$ blue pigment.

Sheet 3: commercial sheet with partial (85\%) UV-B absorbance (commercial control).

Sheet 4: same as $3+$ blue pigment.

Sheet 5: with UV-B absorber, blocking all $(100 \%)$ UV-B transmittance.

Sheet 6: same as $5+$ blue pigment.

Growth chamber experiments. Effect of $P E$ sheets on colonization. Inoculated seedlings of cucumber (cv. Delilah) with a local isolate of $P$. cubensis were used to obtain fresh sporangia, which were gently brushed into distilled water with Tween 20 . For the colonization test, the second leaf of each of six cucumber plants (at the threeleaf stage) was artificially inoculated by spraying $2 \mathrm{ml}$ of a sporangial suspension of $P$. cubensis containing $5 \times 10^{4}$ sporangia on a leaf target area $\left(4.5 \mathrm{~cm}^{-2}\right)$ by means of a quantitative inoculator (21). The inoculated plants were then moved into mini-tunnels $(40 \times 60 \mathrm{~cm})$, which were covered with the tested sheets. The mini-tunnels were kept in a growth chamber maintained at $25^{\circ} \mathrm{C}$ illuminated by VHO GroLux fluorescent tubes and 40-W incandescent lamps with a 16-h photoperiod at a light intensity of 14,000 lux, and kept at 50 to $60 \% \mathrm{RH}$. Symptom development was rated using a combined scale for (i) area infected ( 0 to 4 , where $0=$ no symptoms, $1,2,3$, and $4=$ $25,50,75$, and $100 \%$ infected, respectively) and (ii) color of infected area (0 to 3 , where $0=$ no symptoms, $1=$ yellowish,

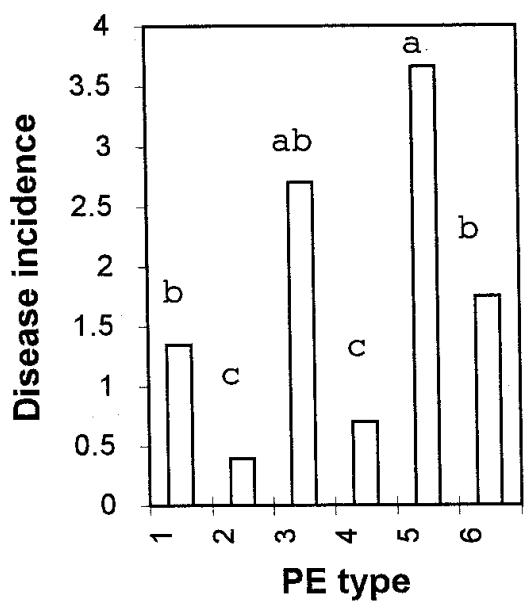

Fig. 2. The effect of photoselective polyethylene (PE) sheets on colonization of Pseudoperonospora cubensis. Leaf 2 of each of six cucumber plants (at the three-leaf stage) was artificially inoculated by spraying $2 \mathrm{ml}$ of sporangial suspension of $P$. cubensis on the leaf target area $\left(4.5 \mathrm{~cm}^{2}\right)$ with a quantitative inoculator. The inoculated plants were then kept in a growth chamber maintained at $25^{\circ} \mathrm{C}$, and symptom development was rated by using a combined scale for size of infected area ( 0 to 4 ) and color of infected area (0 to 3$)$. Disease incidence is expressed by the multiple value of the color and the infected area of each leaf. The experiment was conducted three times, and Duncan's multiple range test was used to analyze the data.

Fig. 1. Light transmittance through photoselective polyethylene (PE) films. Six types of PE sheets with or without a blue pigment that absorbs part of the yellow-green spectrum (530 to $600 \mathrm{~nm}$ ), in combination with various levels of UV-B (280 to $320 \mathrm{~nm}$ ) absorbance, were tested. Light transmittance was recorded using a Cary 2300 spectrometer. 
2 = yellow, 3 = brown (total necrosis). Disease incidence is expressed by the product of the color and the infected area values of each leaf or seedling previously described (17). Each experiment was conducted three times, and Duncan's multiple range test was used to analyze the data.

Effect of PE sheets on sporangial production. Ten disks ( $5 \mathrm{~mm}$ diameter) were collected from each of 10 cucumber infected leaves having uniform chlorotic symptoms of $P$. cubensis. Leaf disks were placed on moist filter paper in petri dishes (without covers), wrapped with the tested sheets, and incubated for $24 \mathrm{~h}$ under continuous light in a growth chamber (as mentioned above) at $18^{\circ} \mathrm{C}$. The $\mathrm{RH}$ within the petri dishes in this period was $100 \%$. Sporangia that appeared on the abaxial side of the leaf-disks were then gently brushed into distilled water with Tween 20 and counted with the aid of a hemacytometer. The experiment was conducted three times, and Duncan's multiple range test was performed.

Field experiments. Effect of photoselective PE sheets on downy mildew development and yield in cucumbers. Location 1 (Ginegar, winter 1993): Sheets 1, 3, 4, 5, and 6 were used to cover four different greenhouses per sheet, which were arranged in a randomized block design experiment. Cucumbers (cv. Lina) were planted (mid-October) and received a commercial treatment against insects and only two applications of fungicides against downy mildew (fosetyl $\mathrm{Al}$ on 6 December and Mancor on 20 December). Sixteen plants in each greenhouse were marked and used for disease ratings. Disease incidence was rated using a 0 to 10 scale based on

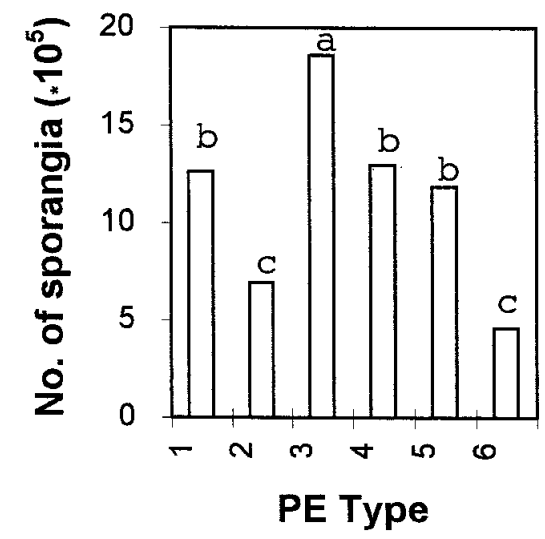

Fig. 3. The effect of photoselective polyethylene (PE) sheets on sporangial production of Pseudoperonospora cubensis. Ten disks (5 mm diameter) were collected from each of 10 different chlorotic cucumber leaves infected with $P$. cubensis. Leaf disks were placed in wet petri dishes (without covers), wrapped in the tested sheets, and incubated for $24 \mathrm{~h}$ under continuous light in a growth chamber maintained at $18^{\circ} \mathrm{C}$. Sporangia were counted with the aid of a hemacytometer. The experiment was conducted three times, and Duncan's multiple range test was used to analyze the data.
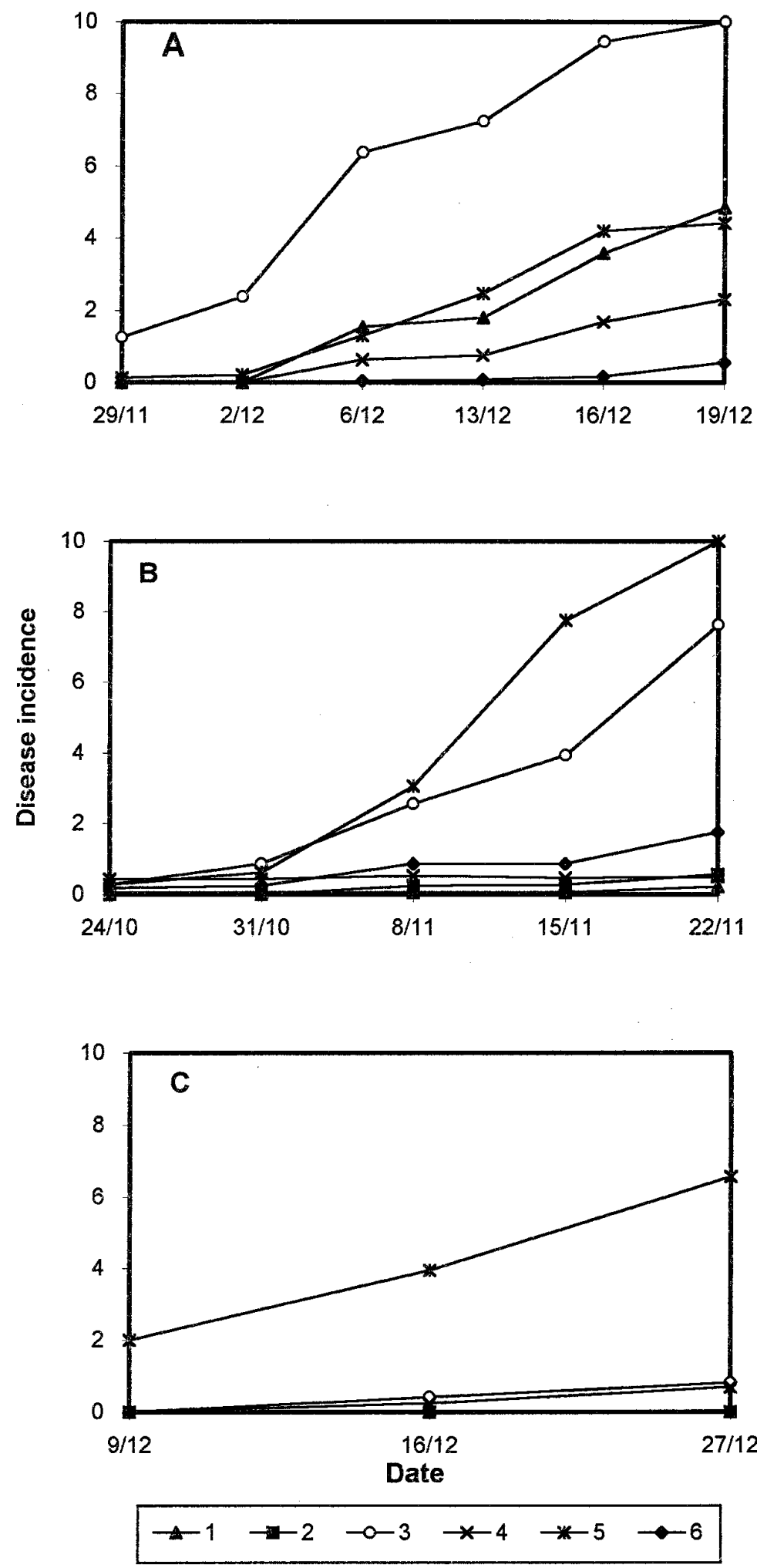

Fig. 4. The effect of photoselective polyethylene sheets on downy mildew development in cucumbers. (A) Location 1 (Ginegar, winter 1993). Sheets 1, 3, 4, 5, and 6 were used to cover four different greenhouses, which were arranged in a complete randomized block design. Sixteen cucumber plants (cv. Lina) in each greenhouse were marked and used for disease ratings. Disease incidence was rated on a 0 to 10 scale based on percentage of diseased parts of each tested plant. Weight of harvested fruits was recorded for each greenhouse and is presented as average of total yield for each sheet. Duncan's multiple range test was used to analyze the data. (B) Location 2 (Ahituv, winter 1993). Each sheet was used to cover two different tunnels $(40 \times 3.5 \mathrm{~m})$. Twelve cucumber plants (cv. Hassan) in each house were marked and used for disease rating. Disease incidence was recorded as described. Weight of cucumbers was recorded for each greenhouse and is presented as average total yield for each sheet. (C) Location 3 (Ibthan, winter 1993). Each sheet was used to cover two different tunnels $(40 \times 3.5 \mathrm{~m})$. The number of tested plants and disease rating and yield measurements were as described for location 2. 
the percentage of diseased parts of each tested plant. The weight of harvested fruits was recorded for each greenhouse and presented in $\mathrm{kg} / \mathrm{m}^{2}$ for each sheet. Aspi- rated dry and wet bulb thermocouples were placed at $1.5 \mathrm{~m}$ height in the center of each greenhouse. Data were collected at 5-min intervals in a data logger and were ana- lyzed routinely for temperature and $\mathrm{RH}$ values.

Location 2 (Ahituv, winter 1993): Each of the six sheets was used to cover two
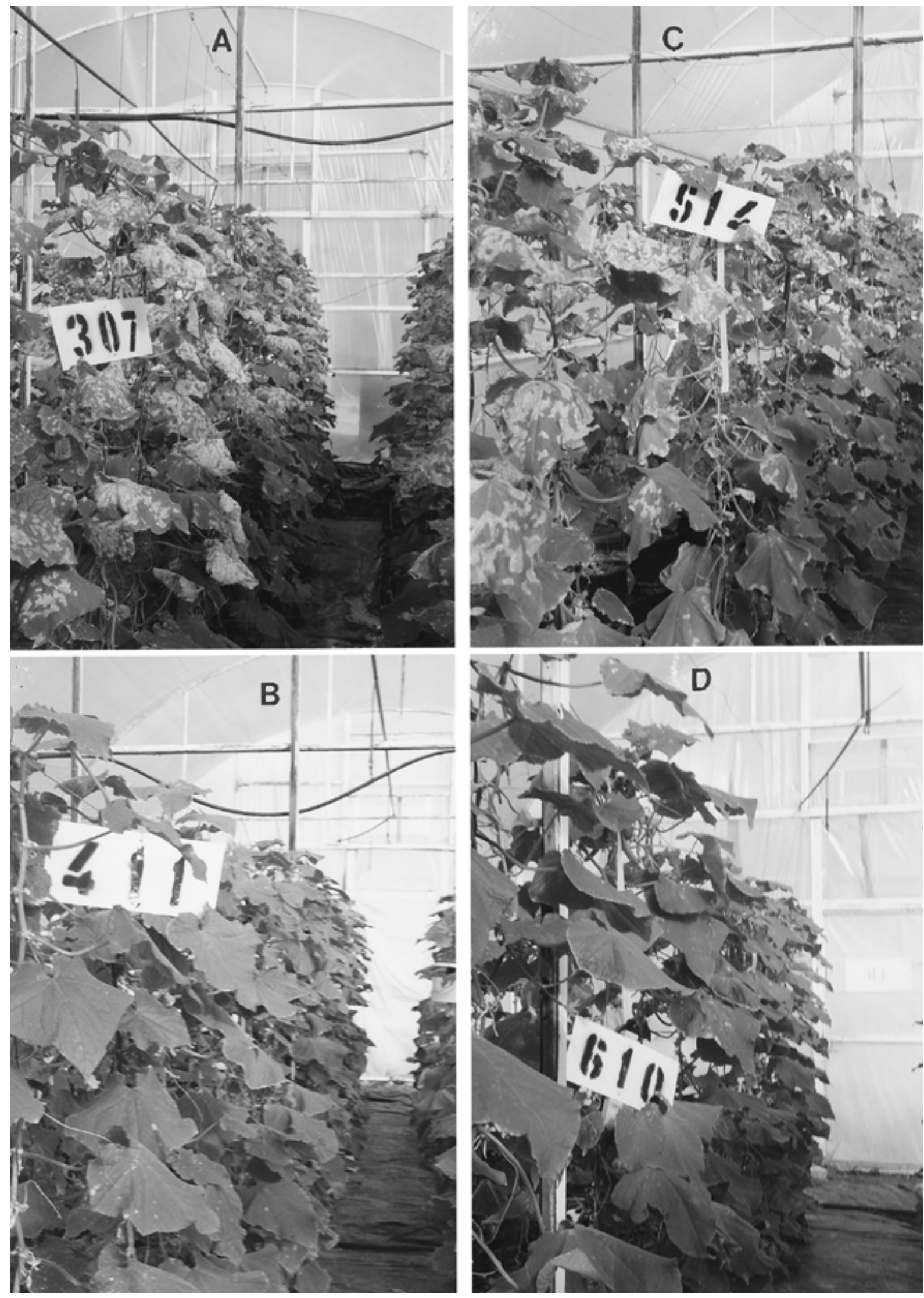

Fig. 5. The effect of photoselective polyethylene sheets on downy mildew development in cucumbers. Location 1 (Ginegar, winter 1993). Photographs were taken at the last evaluation (12 December). 
different tunnels $(40 \times 3.5 \mathrm{~m})$ at Ahituv. Cucumbers (cv. Hassan) were planted (mid-September) and handled by the grower according to commercial practices, including routine treatments against insects and one application of Aliette (25 October) and one of Mancor (11 November) against downy mildew. Twelve plants in each greenhouse were marked and used for disease ratings. Disease incidence was recorded as described above. The weight of cucumbers was recorded for each greenhouse and presented in $\mathrm{kg} / \mathrm{m}^{2}$ for each sheet.

Location 3 (Ibthan, winter 1993): Each of the six sheets was used to cover two different tunnels $(40 \times 3.5 \mathrm{~m})$ at Ibthan. Cucumbers (cv. Hassan) were planted (mid-October) and handled by the grower according to commercial practice, including routine treatments against insects and two applications of fungicides (fosetyl Al, 2 December, at the first appearance of symptoms, and 12 December). The number of tested plants and disease rating and yield measurements were as described for location 2.

Other locations (winter 1991 and winter 1994): Each of sheets 3, 5, and 6 was used to cover two different tunnels $(40 \times 3.5 \mathrm{~m})$ at two different locations under commercial conditions and was handled by the growers (winter 1991). To provide more data, sheets 4 and 6 were tested again (winter 1994) in two other locations and were again handled under commercial conditions by the growers. Disease rating and yield were recorded as described above.

\section{RESULTS}

Growth chamber experiments. Effect on colonization. The effects of the combination of blue pigment and various levels of UV-B spectrum absorption on the colonization of $P$. cubensis on the second cucumber leaf are presented in Figure 2. For each UV absorption level, lower disease incidence was detected under the sheet with the blue pigment, while filtration of the UV spectrum enhanced the colonization of the pathogen, which was directly related to the level of the UV spectrum removal.

Effect on sporangial production. The effects of various combinations of blue pigment and UV absorber (UVA) on sporangial production of $P$. cubensis are shown in Figure 3 . The addition of the blue pigment resulted in significant inhibition of sporangial production of $P$. cubensis at each level of UV-B transmittance, while UV-B effect is not consistent. Partial UV-B absorption, as in the commercial sheet, promotes greater sporangial production than either complete absorption or no absorption.

Field experiments. Location 1. Significant reduction in the disease incidence of downy mildew was recorded under all the blue sheet combinations (Fig. 4A), and photographs of four combinations are presented in Figure 5. In addition, the appearance of the first symptom-bearing plants was delayed under the blue covers by 8 to 18 days compared with the commercial control (film 3).

However, regardless of disease incidence, there were no significant differences among yield values obtained under the various sheet combinations (Fig. 6A). Temperature and $\mathrm{RH}$ values were essentially identical under the various sheets (data not presented).

Locations 2 and 3. Reduction in disease incidence and late appearance of symptombearing plants were recorded in both locations under the blue films (Fig. 4B and C). It should be indicated that a viral disease, which was later identified as cucurbit yellowing virus (CYV) (1), was observed on most of the plants at the early stage of growth under sheets 1 and 2 but was only sporadic under the other sheets. Regardless of the differences in disease incidence, there were no significant differences in the yields obtained in these locations under all combinations of sheets (Fig. 6B and C).

Other locations (winter 1991 and winter 1994). Because the same trends for both disease incidence and yield were obtained in these experiments, the data are not presented.

\section{DISCUSSION}

Possible control of several pathogens in the greenhouse by means of photoselective cladding materials that interfere with the life cycle of the causal organisms has been reported previously $(10,11,16,17,20,24)$. The control of downy mildew, however, has not been investigated in this respect and is generally practiced by intensive use of fungicides.

Since $P$. cubensis is an obligatory parasite, in vitro study of its reaction to monochromatic light is rather complicated. Because illumination with blue light was previously found to be inhibitory to sporangial production by $P$. cubensis in infected cucumber leaves (11), we tried to study the effects of blue pigment, in various combinations with a UV-B absorber, added to PE films to learn their effect on two major stages of the life cycle of the pathogen, namely colonization and sporangium formation.

Both sporangial production and colonization of $P$. cubensis were inhibited in vitro by light filtered through a blue pigment (Figs. 2 and 3). UV-B absorption was not consistent in inhibiting sporangium formation (Fig. 3) as was observed for colonization (Fig. 2), but the addition of the blue pigment to all levels of UV-B absorption inhibited both sporulation (Fig. 3) and colonization stages (Fig. 2). In spite of the fact that UV-B absorption per se was not effective against colonization or sporangial production of $P$. cubensis, we decided to test the same types of films in greenhouse experiments because of the effectiveness of UV-B absorption in preventing another common disease of greenhouse-grown cucumbers-gray mold.

When tested on walk-in tunnels, partial light absorption using a blue pigment, combined with complete removal of the UV-B part of the spectrum (film 6), was efficient in both delaying the onset of first symptoms and reducing the disease severity in all of the greenhouse experiments (Fig. 4). We ruled out the possibility of coincidence by conducting the experiments at five locations, during four seasons, and with three cultivars (Figs. 4 and 5, and
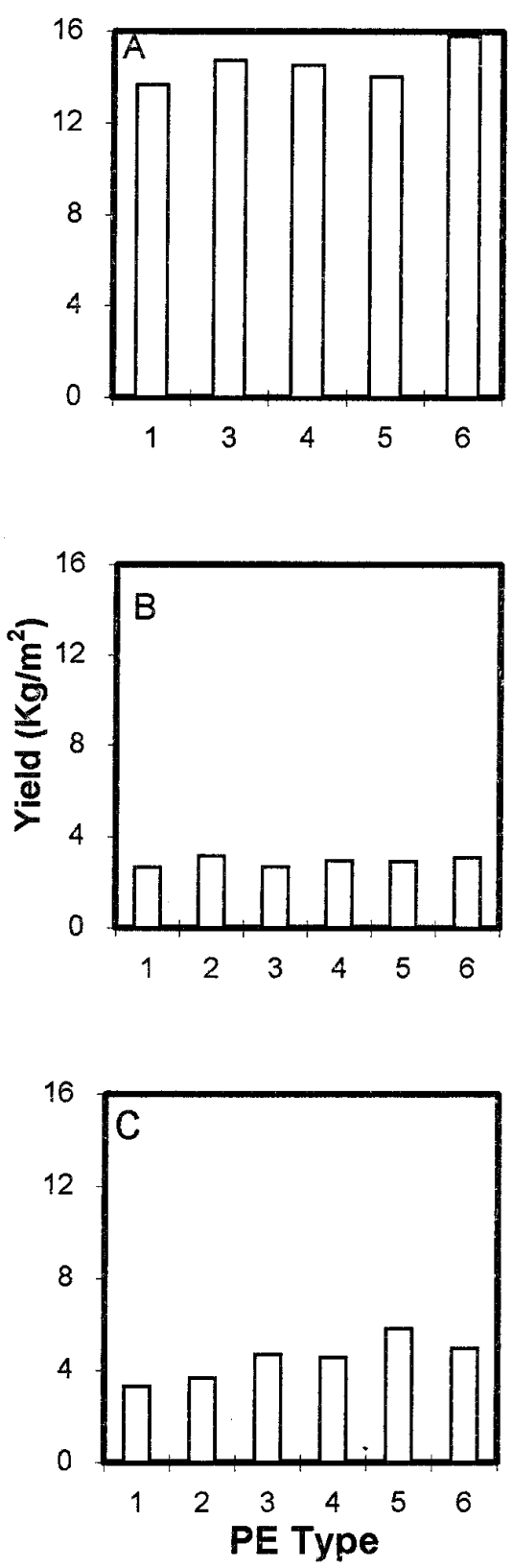

Fig. 6. The effect of photoselective polyethylene (PE) sheets on yield of cucumbers. (A) Location 1 (Ginegar, winter 1993); (B) location 2 (Ahituv, winter 1993); (C) location 3 (Ibthan, winter 1993). 
unpublished data). As most of the plants under sheet 1 in locations 2 and 3 were affected by a viral disease (CYV) at the early stage of growth, low disease incidence of $P$. cubensis was observed possibly due to a cross-protection mechanism against $P$. cubensis induced by the viral infection (25). It was postulated that a vector of this virus requires UV-B in order to identify its host plants. This was recently demonstrated in a similar system (1) and widened the potential use of photoselective films.

Reducing the intensity of light by the blue pigment had no effect on the temperature and $\mathrm{RH}$ in the greenhouse (measurements not presented). It is, therefore, assumed that light is the major controllable factor in the inhibition of the disease in the greenhouse. The addition of the blue pigment lowers light transmissivity of the films in the PAR range. Inevitably, this fact should affect yield negatively. The fact that under the tested conditions yields were not affected by the reduction in PAR is probably due to the positive effect of the blue films on disease severity (Figs. 4 and 5), which compensated for the putative yield losses associated with the lower PAR. Due to commercial constraints, field experiments at locations 2 and 3 were terminated before diseased plants were collapsed. Therefore, correlation between yield and disease incidence was not detectable. Yields similar to the commercial control offer a clear economic advantage because of the decrease in crop protection expenses. The environmental and health advantages are clear as well. Film 6 is now commercially available in Israel.

From preliminary results with higher pigment concentrations, it can be assumed that at approximately $65 \%$ transmittance at $580 \mathrm{~nm}$, sporangial formation will be nullified (data not shown). At this level of PAR absorbance, putative yield losses are greater. Only growers who practice organic agriculture and have a very limited arsenal of eradication means against downy mildew may benefit from such a film.

The presented results imply that any commercial sheet based on this approach should be carefully constructed to minimize PAR absorption and to restrict it to wavelengths less effective in photosynthesis (13). It can be assumed that a pigment with sharper peak of absorption will enable even better disease control combined with lower PAR cost. At present, however, a compromise is necessary between the requirements of suppressive wavebands for fungal colonization and sporulation and maximal PAR needed for yield. The present data suggest an alternative way to control downy mildew that minimizes both chemical expense and environmental hazards.

\section{ACKNOWLEDGMENTS}

The close collaboration with the late R. Bar, N. Even-Dar, Y. Ben-Efraim, D. Assenhiem, M. Schnitzer, and A. Lustig of Ginegar Plastics, Israel, is highly appreciated. We also thank L. Frieman and A. Bar of Newe Ya' ar for technical assistance. This research is partially supported by the Extension Services, Ministry of Agriculture, State of Israel.

\section{LITERATURE CITED}

1. Antignus, Y., Ben-Joseph, R., Mor, N., and Cohen, S. 1995. The use of UV-absorbing films for protection of different crops against virus diseases vectored by Bemisia tabaci. (Abstr.) Phytoparasitica 23:241.

2. Aragaki, M. 1962. Quality of radiation inhibitory to sporulation of Alternaria tomato. Phytopathology 52:1227-1228.

3. Baker, K. F., and Linderman, R. G. 1979. Unique features of the pathology of ornamental plants. Annu. Rev. Phytopathol. 17:253-277.

4. Bewley, W. F. 1923. Diseases of Glasshouse Plants. Benn, London.

5. Dekker, J. 1987. Acquired resistance to fungicides. Annu. Rev. Phytopathol. 14:405-428.

6. Furuya, M. 1986. Photobiology of fungi. Pages 503-520 in: Photomorphogenesis in Plants. R. E. Kendrick and G. H. M. Kronenberg, eds. Martinus Nijhoff, Dordrecht, The Netherlands.

7. Hite, R. H. 1973. The effect of irradiation on the growth and asexual reproduction of Botrytis cinerea. Plant Dis. Rep. 57:131-135.

8. Honda, Y., and Sakamoto, M. 1968. On the blue light inhibition of sporulation in Helminthosporium oryzae. Ann. Phytopathol. Soc. Jpn. 34:328-335.

9. Honda, Y., Sakamoto, M., and Oda, Y. 1968. Blue and near ultraviolet reversible photoreaction on the sporulation of Helminthosporium oryzae. Plant Cell Physiol. 9:603-607.

10. Honda, Y., Toki, T., and Yunoki, T. 1977. Control of gray mold of greenhouse cucumber and tomato by inhibiting sporulation. Plant Dis. Rep. 61:1041-1044.

11. Honda, Y., and Yunoki, T. 1977. Control of
Sclerotinia disease of greenhouse eggplant and cucumber by inhibition of development of apothecia. Plant Dis. Rep. 61:1036-1040.

12. Inaba, T., and Kajiwara, T. 1971. Physiological studies of cucumber downy mildew disease. (In Japanese, with English summary.) Bull. Natl. Inst. Agric. Sci. C 29:29-65.

13. Inada, K. 1976. Action spectra for photosynthesis of higher plants. Plant Cell Physiol. 17:355-365.

14. Jordan, V. W. L., and Hunter, T. 1972. The effect of glass cloche and coloured polyethylene tunnels on microclimate, growth, yield and disease severity of strawberry plants. J. Hortic. Sci. 47:419-426.

15. Kumagai, T. 1984. Mycochrome system in the induction of fungal conidiation. Pages 29-38 in: Blue Light Effect in Biological Systems. H. Senger, ed. Springer Verlag, Berlin.

16. Raviv, M., and Reuveni, R. 1995. Modification of sunlight spectrum by greenhouse cladding materials for the control of foliar diseases. Pages 339-350 in: Novel Approaches to Integrated Pest Management. R. Reuveni, ed. CRC Press, Boca Raton, FL.

17. Reuveni, R. 1983. Resistance reaction of Cucumis melo to inoculation with Pseudoperonospora cubensis. Ann. Appl. Biol. 102:533-537.

18. Reuveni, R., and Raviv, M. 1992. The effect of spectrally-modified polyethylene films on the development of Botrytis cinerea in greenhouse grown tomato plants. Biol. Agric. Hortic. 9:77-86.

19. Reuveni, R., Raviv, M., and Bar, R. 1989. Sporulation of Botrytis cinerea as affected by photoselective polyethylene sheets and filters. Ann. Appl. Biol. 115:417-424.

20. Sasaki, T., Honda, Y., Umekawa, M., and Nemoto, M. 1985. Control of certain diseases of greenhouse vegetables with ultraviolet-absorbing film. Plant Dis. 69:530-533.

21. Schein, R. D. 1964. Design, performance and use of a quantitative inoculator. Phytopathology 54:509-513.

22. Skylakakis, G. 1983. Theory and strategy of chemical control. Annu. Rev. Phytopathol. 21:117-135.

23. Tan, K. K., and Epton, H. A. S. 1973. Effect of light on the growth and sporulation of $\mathrm{Bo}$ trytis cinerea. Trans. Br. Mycol. Soc. 61:145157.

24. Vakalounakis, D. J. 1991. Control of early blight of greenhouse tomato, caused by Alternaria solani, by inhibiting sporulation with ultraviolet-absorbing vinyl film. Plant Dis. 75:795-797.

25. Ye, X. S., Strobel, N., and Kuc, J. 1995. Induced systemic resistance (ISR): Activation of natural defense mechanisms for plant disease control as part of integrated pest management (IPM). Pages 95-113 in: Novel Approaches to Integrated Pest Management. R. Reuveni, ed. CRC Press, Boca Raton, FL. 